teaching in this region, eight colour plates of surgical anatomy are included, a luxury which is not usually considered necessary in British surgical texts. The introductory chapters on basic considerations in surgery are excellent but the whole book presents a compromise between the elementary facts that the student nurse needs to know and the technical details, including operative procedures, essential for the postgraduate. Typical of the problems besetting the editor is the attempt to condense the whole of orthopaedics and fractures into a couple of dozen pages. One volume, even one as thick as this, cannot include all things for all men.

\section{Compliance with Therapeutic Regimens}

By David L. Sackett and R. Brian Haynes. Pp. xiv + 293, illustrated, hard cover. The Johns Hopkins University Press, Balitmore \& London, 1976. £12.00.

This book, which originated in a 'Workshop/Symposium' held at McMaster University, is an attempt to review the literature on compliance, and give a scientific basis to the study of patient behaviour. Not surprisingly, the authors have found considerable difficulty in measuring, predicting or understanding human behaviour.

It appears that very few factors can be found reproducibly to influence patient co-operation. The few situations that the authors are able to say reliably improve compliance include admission to hospital, attending of day-centres and supervised injections. Patient education, it would appear, may help and yet seems unrelated to information retained.

In the face of an apparently very bleak situation, the authors manage to retain endless enthusiasm for schemes that their reviews have shown either to fail or at best give inconclusive results. As for any new approaches to the subject, they appear to have little to suggest: the lengthy and rather tedious recommendations for future research are often primarily concerned with repeating old studies such that the data of different centres might at least be comparable.

In summary, a rather unsatisfactory account, providing little if any help with the equally unsatisfactory problem of patient compliance.

\section{Current Trends in the Management of Breast Cancer}

Edited by $R$. Robinson BaKer. Pp. viii +159 , illustrated, hard cover. Baillière Tindall, London, 1977. $£ 9.75$ cased.

Since breast cancer is the commonest cause of death from malignant disease in women in the United Kingdom, with numbers actually increasing annually, and since there is little if any evidence that the prognosis of a patient with a breast tumour has improved over the last few decades, medical practitioners and specialists alike will naturally be anxious to read any new publication in this important field. This monograph represents a team effort from the prestigious Johns Hopkins School of Medicine, Baltimore. There is an excellent account of the epidemiology of the disease followed by a most useful review of the pathology of breast cancer and related conditions, illustrated with excellent histological photographs. The third section deals with radiological examination but one wonders if our National Health Service can afford the author's advice to carry this out yearly as a screening programme in women over 50 years, or indeed if this is really justified by the reported results. Thermography is very rightly not considered a reliable technique for detecting breast cancer. The section on clinical management of the primary breast tumour is rather disappointing; perhaps it reflects the present chaotic situation in which surgeons really do not know what to do best for their patients. It is rather surprising that 'frozen section and proceed to mastectomy' is rather rejected in favour of preliminary biopsy; perhaps this represents a difference in the patient's attitude to the disease on either side of the Atlantic Ocean. Cytotoxic drugs are advised, on the scantiest of statistical evidence, in patients with lymph node involvement and there is no discussion of the essential need for continued studies by controlled trials in this interesting and highly controversial field. The final chapter on the management of metastatic or recurrent disease is interesting but surprisingly brief, with radiotherapy only mentioned en passant. Each chapter has an extensive bibliography which is almost confined to publications from the U.S.A. This is an interesting book but readers should not expect to find the answers to their clinical problems within its pages.

\section{Dermatology}

(Tutorials in Postgraduate Medicine Vol. 6). Edited by R. Marks and P. D. Samman. Pp. xi + 501, illustrated, hard cover. William Heinemann Medical Books, London, 1977. $£ 11.50$.

The editors and publishers have produced a new, mediumsized textbook on dermatology. It is considerably more detailed and scientifically orientated than current books aimed mostly at the undergraduate, yet nearly as informative as the much larger or double-volume tomes that have appeared both here and in the U.S.A. in the last decade or so. It will appeal particularly to the younger members of hospital dermatological departments, including those overseas, as a chapter on tropical dermatology is included.

Curiously, the review copy twice lists the contributors, most of whom are associated with the Institute of Dermatology in London, but omits the contents page. In the preface the editors state "that dermatologists are beoming possessed by an evangelical zeal in the dissemination of knowledge concerning their subject' so, clearly, they did not have to wait long for the contributors to send in their respective chapters. Nevertheless, this 1977 book gives no account of the PUVA treatment of psoriasis, nor of zinc for acrodermatitis enteropathica. Scabies is too briefly described and that in the chapter on tropical dermatoses. Dr Marks implies that the systemic effects from absorption of topical steroids have been inconclusively studied. Yet the information about this is reasonably precise and has helped to reduce excessive prescribing of the very potent steroids. Some of the black and white illustrations have not reproduced well and others are not as good as those in much older books, long before there were high-powered departments of Medical Illustration.

Dermatology conveys some of the excitement and interest which has occurred in the speciality by the contemporary investigational and experimental approach. The book is recommended and should find a place in every hospital and postgraduate medical centre library.

\section{Developmental Paediatrics}

(Postgraduate Paediatrics Series, General Editor: John Apley). By K. S. Holt. Pp. ix +311 , illustrated, hard cover. Butterworths, Sevenoaks, 1977. $£ 5.50$.

Since the first volume was published in 1971, the Postgraduate Paediatrics Series of publications under the general editorship of Dr John Apley has already gained a well deserved reputation. Professor Kenneth's Holt's contribution on Developmental Paediatrics maintains the high standard already set. One can discern in the present volume the influence of Professor Ronald Illingworth of Sheffield, in whose department Professor Holt worked before his appointment as Director of the Wolfson Centre.

Professor Holt quite correctly restricts his text to the physical and intellectual aspects of child development. He describes the essential aspects of normal and abnormal development which must be the basic knowledge of those who participate in multidisciplinary assessment of children. It is not a criticism of this book but possibly of society in general that handicap is seen as a physical or intellectual 